\title{
Application of microorganisms towards synthesis of chiral terpenoid derivatives
}

\author{
Renata Kuriata-Adamusiak • Daniel Strub • \\ Stanisław Lochyński
}

Received: 16 April 2012 /Revised: 13 July 2012 / Accepted: 13 July 2012 /Published online: 31 July 2012

(C) The Author(s) 2012. This article is published with open access at Springerlink.com

\begin{abstract}
Biotransformations are a standard tool of green chemistry and thus are following the rules of sustainable development. In this article, we describe the most common types of reactions conducted by microorganisms applied towards synthesis of chiral terpenoid derivatives. Potential applications of obtained products in various areas of industry and agriculture are shown. We also describe biological activity of presented compounds. Stereoselective hydroxylation, epoxidation, Baeyer-Villiger oxidation, stereo- and enantioselective reduction of ketones, and various kinetic resolutions carried out by bacteria and fungi have been reviewed. Mechanistic considerations regarding chemical and enzymatic reactions are presented. We also briefly describe modern approaches towards enhancing desired enzymatic activity in order to apply modified biocatalysts as an efficient tool and green alternative to chemical catalysts used in industry.
\end{abstract}

Keywords Biotransformations · Terpenoids ·

Microorganisms $\cdot$ Stereochemistry

\section{Introduction}

Terpenoids are group of compounds of natural origin biosynthesized from isopentenyl pyrophosphate (IPP) and dimethylallyl pyrophosphate (DMAPP). Structurally,

\footnotetext{
R. Kuriata-Adamusiak • D. Strub · S. Lochyński $(\bowtie)$

Department of Bioorganic Chemistry, Faculty of Chemistry,

Wrocław University of Technology,

Wyb. Wyspiańskiego 27,

50-370 Wrocław, Poland

e-mail: stanislaw.lochynski@pwr.wroc.pl

S. Lochyński

Institute of Cosmetology, Wrocław College of Physiotherapy,

Kościuszki 4,

50-038 Wrocław, Poland
}

they are saturated and unsaturated cyclic and aliphatic hydrocarbons with varying degrees of oxygenation, including alcohols, aldehydes, ketones, and carboxylic acids. Terpenoids can be divided into subclasses according to number of isoprene units in their structure. Condensation of IPP and DMAPP leads to geranyl pyrophosphate (GPP, $\mathrm{C}_{10}$ ) which is a precursor in biosynthesis of monoterpenoids and iridoids. Reaction between GPP and IPP gives farnesyl pyrophosphate (FPP, $\mathrm{C}_{15}$ )-precursor in biosynthesis of sesquiterpenoids and sesquiterpenoid lactones. Condensation of two units of FPP leads to triterpenoids $\left(\mathrm{C}_{30}\right)$. Among them are limonoids, cardenolides, quassinoids, cucrbitacins, saponins, and phytosterols. From terpenoids, we can also distinguish diterpenoids class $\left(\mathrm{C}_{20}\right)$ which originate from geranylgeranyl pyrophosphate.

Terpenoids are applied in varying areas of human interest: flavor and fragrance industry-volatile monoterpenoids like citronellal, citral, geraniol, (-)-menthol; pharmaceutical industry-anticancer agent taxol; agriculture-iridoids and sesquiterpene lactones which are used as insect feeding deterrents (Walton and Brown 1999). Despite variety of applications and activity of terpenoids, there are attempts to modify their base structure to enhance their properties. This can be achieved by applying chemical synthesis or biotransformations. In many cases, organic synthesis is not a method of choice of structural modifications of complicated terpenoids due to side reactions, low regio- and enantioselectivity, low yields, and application of expensive catalysts comprising transition metal ions.

Microorganisms have been used for a long time in household and industry, where they play indispensable role. Their application extends to food processing as well as to catalysis of complicated chemical reactions.

Undisputed advantages of catalytic use of whole cells of microorganisms are their broad substrate specificity, 
possibility to act under mild conditions, and the fact that they do not require regeneration of cofactors comparing to isolated enzymes. Application of microorganisms is more economical than the use of enzymes but does not always result in similarly high enantioselectivity of catalyzed reactions (Nakamura et al. 2002; Beloqui et al. 2008). In order to minimize occurrence of side reactions and to enhance enantioselectivity manipulation of reaction conditions have been elaborated, to mention only stereochemical control as well as addition of organic solvents or enzyme inhibitors (Nakamura 1998).

Despite several disadvantages, microbial transformations are commonly used in organic synthesis towards preparation of homochiral compounds used in agriculture, pharmaceutical, cosmetic, and food industry. In our previous papers, we described microbiological methods of obtaining new terpenoid derivatives with biological activity such as odorants (Kuriata et al. 2010; Kuriata-Adamusiak et al. 2011) and insectfeeding deterrents (Wincza and Lochyński 2012).

In this paper, we have described five main reaction types that microorganisms can conduct on terpenes and terpenoids. They are stereoselective hydroxylation, epoxidation, Baeyer-Villiger oxidation, stereo- and enantioselective reduction of ketones, and kinetic resolution.

In the literature, we can find several reviews about biotransformations of terpenoids (de Carvalho and da Fonseca 2006; Ishida 2005; Bicas et al. 2009). De Carvalho and da Fonseca show many examples of biotransformations by different microorganisms resulting in terpenoid derivatives with mainly olfactory properties. Ishida describes biotranformations of terpenoids by mammals, microorganisms, and plant-cultured cells. His work is mainly focused on transformations carried out by mammals. The last one presents only bio-oxidation of terpenoid derivatives especially useful in flavor industry.

Our work is not focused on the only one type of the reaction which microorganisms can carry out on terpenoid derivatives. It can be considered as a brief review regarding most common and applicable reactions with description of organoleptic properties and biological activity. Moreover, we show the stereoselectivity of biocatalysts which is desired in many branches of industry. The goal of our work was to show background to intelligent research planning based on the type of the reaction with green alternative to toxic chemical catalysts. In addition, we describe modern approaches towards enhancing biocatalysts activity by site-directed mutagenesis and directed evolution. These methods may lead to development of procedures for large-scale preparation of industrially relevant terpenoids.

\section{Stereoselective hydroxylation}

Hydroxylation reaction involves direct oxidation of $\mathrm{C}-\mathrm{H}$ bond to corresponding alcohol. This transformation is difficult to achieve chemically due to inertness of $\mathrm{C}-\mathrm{H}$ bonds of saturated hydrocarbons. Different strategies are employed to achieve chemo-, regio-, and enantioselectivity of hydroxylation. Chemical hydroxylations are often run in low substrate conversions to prevent overoxidations. Different oxidation systems show various selectivity towards primary, secondary, and tertiary $\mathrm{C}-\mathrm{H}$ bonds. Exploiting directing groups that can coordinate to metal atoms of catalyst is the most favorable method of enhancing regioselectivity of hydroxylation. Additionally, stereoselectivity of these processes can be achieved with application of chiral auxiliaries (Baran 2009).

Various oxidants can be used to oxidize $\mathrm{C}-\mathrm{H}$ bonds including transition metal catalysts $[\mathrm{Pt}(\mathrm{II}) / \mathrm{Pt}(\mathrm{IV})$ and $\mathrm{Pd}$ (II)/Pd(IV) systems] which are selective towards terminal C-H bonds (Neufeldt and Sanford 2012). For oxidations of secondary and tertiary $\mathrm{C}-\mathrm{H}$ bonds in saturated compounds, dioxiranes are reagents of choice. Dioxiranes are strong oxidants and cannot be applied to hydroxylation of alkenes due to epoxide formation.

Transition metal catalysts are especially useful for synthesis of some steroids from triterpenoids. Mechanism of chemical hydroxylation of a triterpenoid $E$-lupanone oxime with palladium catalyst is a good example of this type of $\mathrm{C}-$ $\mathrm{H}$ bond activation and oxidation (Carr et al. 1988). ELupanone oxime consists of $\mathrm{C}=\mathrm{N}-\mathrm{OH}$ group which is directing sodium chloropalladate to complex with adjacent methyl group. Resulting dimer is complexed with pyridine and $\mathrm{Pd}-\mathrm{C}$ bond is oxidized with lead(IV) acetate to form acylated product in $4 \alpha$-methyl position.

Hydroxylation is the most extensively studied reaction catalyzed by whole cells of microorganisms. Enzymes responsible for these transformations belong to oxygenases family.

Oxygenases use molecular oxygen as an oxidant. They are cytosolic and transmembrane proteins and may lose their activity upon isolation (Holland and Weber 2000). This is the reason why hydroxylation is the least understood reaction conducted by microorganisms. Oxygenases performing hydroxylation reactions use only one oxygen atom to oxidize a substrate and are called monooxygenases. One of the most thoroughly studied monooxygenases are cytochromes P450 (Meunier et al. 2004). They are present in all branches of life. They consist of an Fe(III)-protoporphyrin-IX covalently linked to the protein by the sulfur atom of cysteine. Mechanism of enzymatic hydroxylation involves several oxidation-reduction processes of an iron atom in porphyrin binding site. Presence of a substrate in a binding site results in elimination of complexed water molecule. Next steps 
involve reduction of $\mathrm{Fe}(\mathrm{III})$ to $\mathrm{Fe}(\mathrm{II})$, activation in situ of oxygen molecule to form complexed peroxide radical which is subsequently reduced to peroxide anion. Two protonations of oxygen molecule in peroxo complex result in loss of water and formation of $\mathrm{Fe}(\mathrm{IV})^{+{ }^{\circ}}$ complex which is responsible for hydroxylation of a substrate $\mathrm{R}-\mathrm{H}$.

Hydroxylation allows synthesis of many drug precursors (Holland 1999) and is a useful alternative for preparation of optically active terpenoid compounds (Kołek et al. 2009).

An example of stereoselective hydroxylation of terpenoids is biotransformation of (-)-menthol 1 by 12 isolated species of Rhizoctonia solani (Fig. 1; Miyazawa et al. 2003). (-)-Menthol 1 is a constituent of mint oil; however, its production from natural sources is too low to cover all the needs. It is also possible to synthesize it from (+)-citronellal, thymol or myrcene, which are quite easily available substrates. (-)-Menthol is commonly used as a food, cosmetic, and pharmaceutical additive due to its pleasant flavor and fragrance. Biotransformations of 1 by Aspergillus species (Asakawa et al. 1991), Penicillium species (Esmaeili et al. 2009), and Rhizoctania solani (Miyazawa et al. 2002) are described in literature. For example, Miyazawa et al. have shown that three out of 12 species of $R$. solani produced: (-)-6-hydroxymenthol 2 (65.2\%), (+)-6,8-dihydroxymenthol 4 (32.4\%), and (-)-1-hydroxymenthol $3(18.4 \%)$ are intermediates for syntheses of compounds which can be applied as agents for control of snow blight disease. Corresponding acetates of alcohols 2 and 4 possess equal lytic activity against the fungus Micronectriella nivalis comparing to organocopper agent copper 8-hydroxyquinolate (Miyazawa et al. 2003).

The second example of microbial hydroxylation is biotransformation of (-)- $\alpha$-pinene 5 by fungi (Fig. 1). Compound 5 is a major and important constituent of essential oils derived from plants. Microbial transformation of 5 by Botrytis cinerea resulted in obtaining $(1 R, 3 S, 5 R)$ trans- $\beta$-pinen-3-ol $6(10 \%)$ and $(1 S, 2 R, 5 S)$-trans-7-oxoverbenol 7 (16\%; Farooq et al. 2002). Activity of 6 and 7 was not elucidated but it would be interesting to evaluate fragrance and antifungal potential in regard to structural modification.

\section{Epoxidation}

Oxidation of a double bond is a useful tool in organic synthesis. Epoxides are intermediates in preparation of biologically active molecules (Lochyński et al. 2002; Moniczewski et al. 2011) including aminoalcohols, diols and hydroxyazides. Most commonly used epoxidation reagents for preparation of racemic epoxides are hydrogen peroxide and peracids due to their low cost. High degree of polarization of peracids allows addition of electrophilic oxygen to an alkene and shifting proton simultaneously. Described reagents are not suitable for epoxidation of substrates comprising multiple double bonds in their structure due to lack of regioselectivity of peracids. In addition, if optically pure epoxides are desired, hydrolytic kinetic resolution of racemic oxiranes with Jacobsen's catalyst must be employed. For chemical preparation of complex optically active epoxides transition, metal catalysts are employed including vanadyl acetylacetonate $\left[\mathrm{VO}(\mathrm{acac})_{2}\right]$ (Itoh et al. 1979) and titanium isopropoxide $\left[\mathrm{Ti}(\mathrm{O} i \mathrm{Pr})_{4}\right]$ with salalen ligands (de Faveri et al. 2011). When alkene is sterically hindered in proximity of a double bond, dioxiranes can be applied for epoxidations with a fair to good stereoselectivity due to electrophilic attack on less hindered face of a substrate (Adam et al. 1999).
Fig. 1 Biotransformation of $(-)$-menthol by $R$. solani and $(-)-\alpha$-pinene by $B$. cinerea
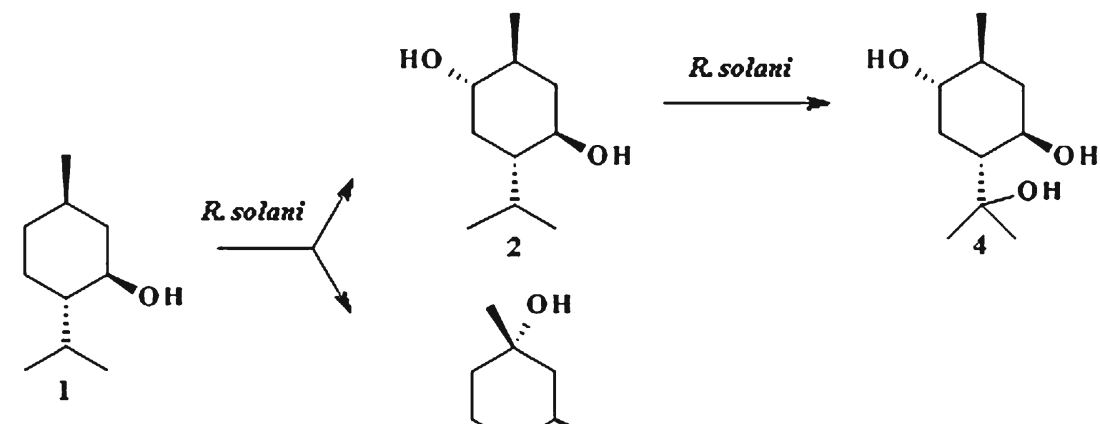<smiles>CC(C)[C@H]1CC[C@@](C)(O)C[C@H]1O</smiles>
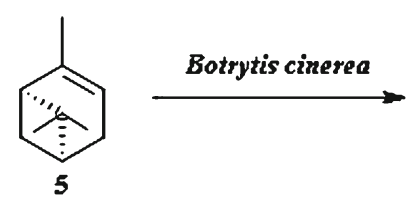
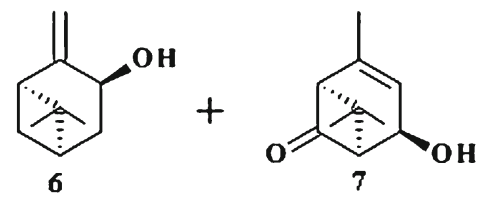
Biocatalytic oxidation of $\mathrm{C}=\mathrm{C}$ bond is catalyzed by oxygenases and peroxidases, which results in production of epoxides with high enantiomeric and diastereomeric excess. Peroxidases use hydrogen peroxide as an oxidant, a process which decreases stability of forming epoxides for their further enzymatic transformations. Peroxidases are usually cytochrome P450 enzymes which contain heme prosthetic group. Iron atom is also coordinated with sulfur atom of protein's cysteine. Peroxidases are able to incorporate hydrogen peroxide to form $\mathrm{Fe}(\mathrm{III})$-hydroperoxide complex which performs attack on double bond of an alkene (de Maria et al. 2010). Oxygenases employ molecular oxygen, which is activated at the active site of the enzyme. Activation in situ results in fewer side reactions. Mechanism of epoxidation by monooxygenases is similar to hydroxylation. In this case, the active agent which reacts with substrate is also $\mathrm{Fe}(\mathrm{IV})^{+^{\circ}}$ complex (Vaz et al. 1998).

Biotransformations of alkenes leading to epoxides require fast removal of products due to low stability of oxiranes in water solutions. In addition, high concentration of substrates and products may decrease enzyme activity. When designing high-scale biocatalytic epoxidations, it is necessary to adjust carefully reaction conditions in order to obtain higher yields (Li et al. 2002).

There are many literature examples describing preparation of terpenoid epoxides via biotransformations (Fraga et al. 2005). Over 60 fungi species were tested by Demyttenaere et al. for their capability of transforming $(R)-(+)$ - and $(S)-(-)$-limonene, which yielded trans and cis epoxides using solid-phase microextraction as the monitoring technique (Fig. 2). Products of biotransformation of $(R)$-limonene 8 by Penicillium digitatum were mainly $(R)-(+)$ - $\alpha$-terpineol 9 and $\gamma$-terpinene 10 . cis-Limonene oxide cis-11 and trans-limonene oxide trans-11 were the only side products in this reaction (Demyttenaere et al. 2001). Approaches to biosynthesize limonene oxides are relevant due to high repellent activity of cis-11 and trans-11. Limonene oxide is a major constituent of essential oil of the repellent plant Lippia javanica (Omolo et al. 2004). In addition, several international patents regarding application of limonene oxide as insect repellent were prepared.

Another example of microbial epoxidation is biotransformation of unsaturated bicyclic $\gamma$-lactone (Fig. 2). Absidia cylindrospora efficiently transforms $12 \mathrm{a}$ and $12 \mathrm{~b}$ to corresponding trans-epoxylactones $13 \mathrm{a}$ and $13 \mathrm{~b}$ where $13 \mathrm{~b}$ was obtained with $100 \%$ diastereomeric excess (Gładkowski et al. 2007). These compounds were not previously described in literature and there are no information regarding biological activity. Evaluation of antifeedant activity is advisable due to feeding deterrent potency of structurally similar epoxylactones (Dancewicz et al. 2011; Hollauf and Urban 1995).

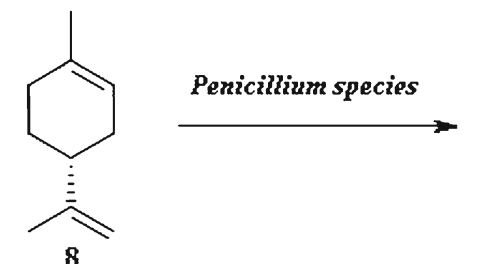<smiles>CC1=CC[C@H](C(C)(C)O)CC1</smiles><smiles>CC1=CCC(C(C)C)=CC1</smiles><smiles>C=C(C)[C@H]1CC[C@@]2(C)O[C@H]2C1</smiles><smiles>C=C(C)[C@@H]1CC[C@@]2(C)O[C@H]2C1</smiles><smiles>[R]C1(C)C=C[C@H]2OC(=O)C[C@@]2([R2])C1</smiles>

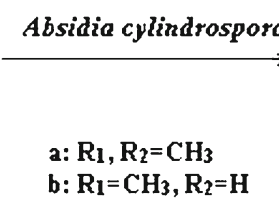

rac $-12 \mathrm{a}, \mathrm{b}$

Fig. 2 Biotransformation of $(R)-(+)$-limonene by Penicillium species and 4,4,6-trimethyl-9-oxabicyclo[4.3.0]non-2-en-8-one with $A$. cylindrospora

Application of microorganisms to obtain epoxylactones is not a method of choice due to opening of oxirane ring followed by rearrangements in reaction conditions.

\section{Baeyer-Villiger oxidation}

Baeyer-Villiger oxidation of linear and cyclic ketones to corresponding esters and lactones is an important reaction in

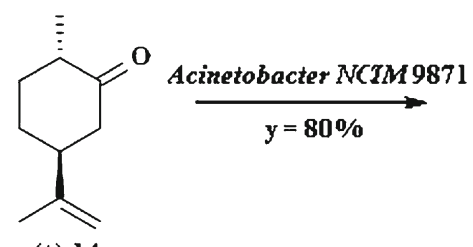

$(+) \cdot 14$
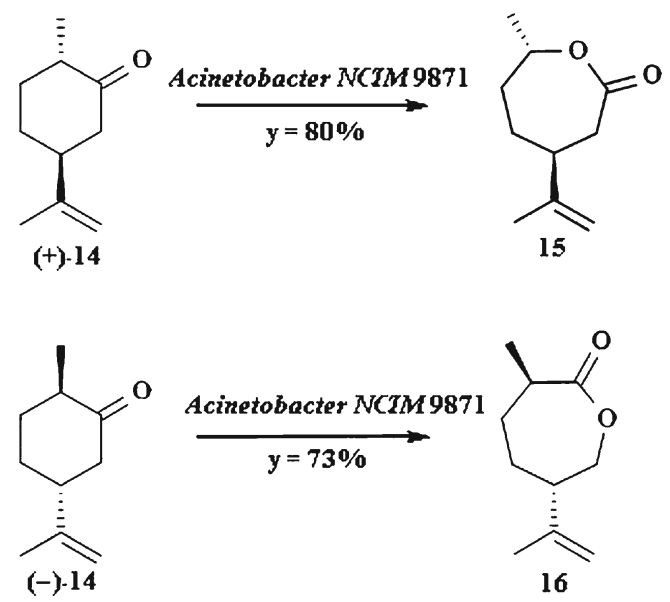

Fig. 3 Biotransformation of ( \pm )-dihydrocarvone by A. calcoaceticus 
Fig. 4 Biotransformation of (4R)-(-)-carvone by $T$. cutaneum CCT 1903

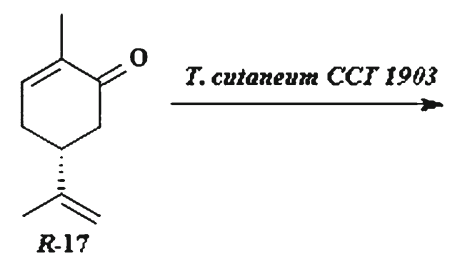<smiles>C=C(C)[C@H](CCC(C)=O)CC(=O)O</smiles>

18<smiles>C=C(C)[C@@H]1CC[C@@H](C)[C@H](O)C1</smiles><smiles>C=C(C)[C@@H]1CC(O)C2(C)OC2C1</smiles>

synthesis of biologically relevant compounds (Mihovilovic et al. 2002; Kamerbeek et al. 2003). Nowadays, pharmaceutical industry demands efficient and environmentally friendly methods for synthesis of optically pure compounds including esters and lactones. The most popular reagents used for Baeyer-Villiger oxidation of ketones are organic peracids. Mechanism of chemical B-V transformation involves protonation of oxygen atom of ketone's carbonyl group and subsequent nucleophilic attack of peroxy anion on positively charged carbon atom of carbonyl. Resulting complex undergoes structural rearrangements. The more substituted group adjacent to carbonyl group the better stabilization potential of positive charge it possesses. This property is responsible for higher migratory aptitude of tertiary carbon atoms over secondary and primary. At the final step, carbonyl group is deprotonated and final product is formed.

Microorganisms that produce Baeyer-Villiger monooxygenases (BVMO) are able to oxidize ketones with high regio- and stereospecifity. This family of enzymes contain flavin mononucleotide (FMN) or flavine adenine dinucleotide (FAD) as a cofactor. FAD or FMN undergoes protonation of nitrogen atom which allows activation of molecular oxygen to form FMN- or FAD-peroxide anion complex. Peroxide anion oxidizes ketone molecule and cofactor is regenerated with subsequent loss of water molecule (Kamerbeek et al. 2003). Microbial B-V oxidation is a good alternative to the reaction catalyzed by toxic organic peracids (Renz and Meunier 1999).

An interesting example of microbial Baeyer-Villiger oxidation is biotransformation of $( \pm)$-dihydrocarvone 14 by
Acinetobacter calcoaceticus, resulting in two lactones (Fig. 3; Ottolina et al. 1996). Monooxygenase from this species exhibits regio- and enantiospecifity. (+)-Dihydrocarvone (+)-14 is transformed into lactone 15 with regard to the higher migratory aptitude of tertiary carbon atom adjacent to the carbonyl group. Biotransformation of this terpene by $A$. calcoaceticus leads to migration of secondary carbon atom during oxidation resulting in lactone 16. This compound is an intermediate in synthesis of (3S,6R)-3-methyl-6-(1-methylethenyl)-9-decen-1-yl acetate which is an attractant for male Aonidiella aurantii - citrus fruits pest and can be applied with combination with other pest control agents (Anderson et al. 1980).

The next example of whole cells Baeyer-Villiger oxidation is biotransformation of (4R)-(-)-carvone $R-17$ by yeast Trichosporum cutaneum CCT 1903 (Fig. 4; Pinheiro and Marsaioli 2007). The main product is hydrogenated lactone $16(31 \%)$ and side products-ketoacid 18 (5\%), dihydrocarveol 19 (3.8\%), and epoxydihydrocarveol 20 (2.2\%).

Biocatalytic Baeyer-Villiger oxidation can obviously be performed also by isolated enzymes. The most common sources of isolated BVMO are species of Acinetobacter (Secundo et al. 1993), Nocardia (Norris and Trudgill 1971), and Pseudomonas (Alphand et al. 1996).

According to the literature (Roberts and Wan 1998; Alphand et al. 1996), it is not possible to state which type of biocatalyst is better. In the case of microbial transformations, we can develop single-step procedures for preparative scale synthesis of chiral terpenoids. In addition, sometimes the use of microorganisms results in formation of an unusual products as it was observed in the case of compound 16 . On
Fig. 5 Biotransformations by Hormonema sp. UOFS Y-0067<smiles>CC(C)=C1CC[C@@H](C)CC1=O</smiles><smiles>C=C(C)[C@@H]1CCC(C)=CC1=O</smiles> 
the other hand, for some substrates, application of isolated monooxygenases is more suitable due to higher yields and stereopurity of synthesized products.

\section{Stereo- and enantioselective reduction of ketones}

Reduction of ketones to corresponding alcohols is the most commonly studied transformation catalyzed by whole cells of microorganisms. Biocatalysts are good alternative to ruthenium (Zanotti-Gerosa et al. 2005), catecholborane (Evans and Hoveyda 1990), or oxazaborolidine reagents (Hirao et al. 1981) popularly used for stereoselective reduction. These reagents use specific interactions between catalysts core and carbonyl group.

Application of whole cells of microorganisms is more convenient method for stereoselective reduction comparing to isolated enzymes due to lack of necessity for using additional system for cofactors regeneration. Many species of fungi and yeast were used for stereoselective reduction of prochiral ketones to optically pure alcohols. Stereoselectivity of ketone reduction depends on specific interactions between enzyme and substrate. This reaction is mostly catalyzed by alcohol dehydrogenase (ADH). These biomolecules are nonheme reductive/oxidative enzymes. ADH's perform hydrogen transfer reaction in presence of coenzyme which acts as a hydrogen donor/acceptor (Naik et al. 2012). The most extensively studied ADH's are medium-chain alcohol dehydrogenases which usually contain two zinc ions (Ying and Ma 2011). The catalytic zinc ion interacts with three ADH's ligands-one histidine and two cysteine residues and a water molecule. Structural zinc site is highly conserved for all classes of alcohol dehydrogenase family and mostly consists of $\mathrm{Zn}$ ion bound to four cysteine residues (Auld and Bergman 2008). Most microorganisms produce several dehydrogenases which are able to oxidize different hydroxyl groups and reduce different carbonyl groups (Carballeira et al. 2009). Most of the applicable alcohol dehydrogenases prefer small, nonpolar, and non-ionisable ketones as substrates (Zhu et al. 2006).

An example of selective bioreduction of terpenes are biotransformations of (-)-menthone 21 and (+)-pulegone 22 to $(1 R, 3 S, 4 S)-(+)$-neomenthol 23 (Fig. 5). Biocatalyst used for this transformation was Hormonema sp. UOFS Y0067 (van Dyk et al. 1998). Mironowicz and Siewinski (1986) reported that cells of Rhodotorula mucilaginosa immobilized on polyacrylamide gel can also be applied for stereoselective reduction of 21 to 23. (+)-Neomenthol 23 possesses antifungal activity against Fusarium verticillioides which causes bakanae disease in rice seedlings and Colletotrichum gloeosporioides-plants pathogenic

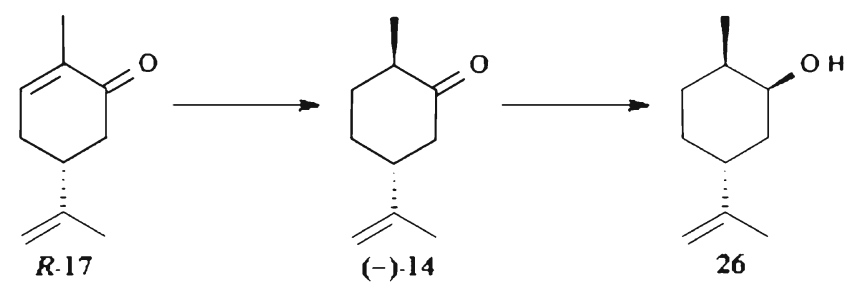

Fig. 6 Reduction of (4R)-carvone by G. butleri, D. grovesii, and $S$. octosporus

fungus infesting apple and mango (Dambolena et al. 2010; Nidiry 2003).

Yeast Hormonema sp. UOFS Y-0067 was also applied for selective reduction of (4S)-isopiperitenone 24 . Product of this biotransformation was exclusively optically pure $(3 R, 4 S)$-isopiperitenol 25 (Fig. 5). Isopiperitenol 25 is an intermediate in preparation of $(-)$-menthol 1 which production from natural sources is not sufficient as was mentioned before (Serra et al. 2003). It is worth noting that configuration of alcohol 25 is opposite to the alcohol 23 despite the fact that stereochemistry of carbon atom C-4 is the same in both substrates.

Another example of selective bioreduction is biotransformation of $(4 R)$-carvone $R-17$. Several microorganisms were screened by Carballeira et al. for ability to perform selective reduction of different ketones and the best results were achieved using species of Gongronella butleri, Diplogelasinospora grovesii, and Schizosaccharomyces octosporus (Carballeira et al. 2004).

In case of biotransformation of ( $4 R$-carvone the first step was hydrogenation of $R-17$ to $(1 R, 4 R)$-dihydrocarvone (-)14 and subsequent stereoselective reduction to $(1 R, 2 S, 4 R)$ dihydrocarveol 26 (Fig. 6). In addition, when G. butleri had been used as biocatalysts, a small amount of side products were present. Dihydrocarveol 26 is a flavoring food additive so environmentally friendly method of its production would be desirable.

The same biocatalysts were used for bioreduction of second isomer of carvone-(4S)-carvone $S$-17. Biotransformation by $D$. grovesii resulted in the formation of allyl alcohol 27 which possesses fragrance resembling that of mint and caraway. It is used in cosmetic industry and as flavor additive in food industry. The same product was obtained in case of using

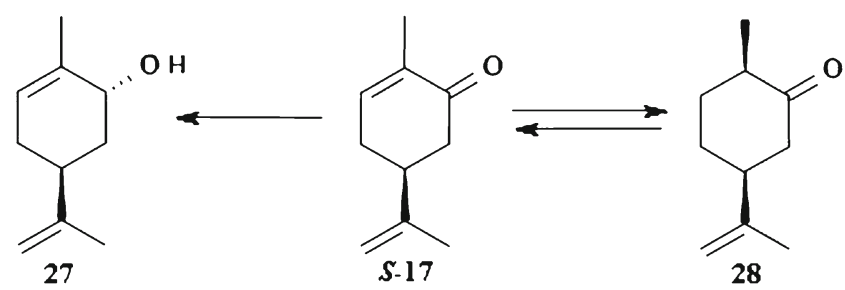

Fig. 7 Biotransformation of (4S)-carvone by G. butleri, D. grovesii, and $S$. octosporus 
G. butleri and S. octosporus. In these cases, they contained traces of additional compounds. (4S)-Carvone was also hydrogenated to $(1 R, 4 S)$-dihydrocarvone 28 in conditions similar to those applied to $R$-isomer but in this case reduction did not occur. It is postulated that unstable primary reaction product $(1 R, 4 S)$-dihydrocarvone is oxidized to $(4 S)$-carvone which is subsequently reduced to secondary stable product $(2 R, 4 S)$ carveol 27 (Fig. 7). Additionally, the factor determining direction of the reaction pathway is stereochemistry at carbon atom $\mathrm{C}-4$.

Summarizing carvone bioreduction, it is seen that reaction pathway is different for each enantiomer. For both isomers the most interesting catalyst was $D$. grovesii which gives maximum yield of alcohol and no side products. Stereochemistry at C-4 carbon atom is a factor determining direction of the reaction pathway due to action of two main enzymes involved in transformations (Fig. 8):

1. enone reductase which in both cases catalyzes reaction to $(1 R, 4 R$ or $S)$-dihydrocarvone (Faber 2000)

2. alcohol dehydrogenase which reduces only one isomer of dihydrocarvone- $(1 R, 4 R)$-dihydrocarvone to dihydrocarveol. It also catalyzes exclusively reduction of carbonyl group of $(4 S)$-carvone to $(2 R, 4 S)$-carveol. The same conclusions were made by van Dyk et al. (1998).

\section{Kinetic resolution}

Nowadays, searching for the new efficient methods for synthesis of optically pure chiral building blocks is of great interest to industrial and academic laboratories (de Carvalho et al. 2002). In the past decade, advances have been made towards asymmetric synthesis but kinetic resolution of racemic mixtures is still the most often applied method for preparation of optically pure compounds in industry (Robinson and Bull 2003).

An example of efficient bioresolution of terpenoid substrate is biotransformation of (+)-1,2-epoxylimonene used in form of mixture of isomers cis-29 and trans-29 in a ratio of $42.2: 55.7$ by applying Rhodococcus erythropolis DCL14 as a biocatalyst (Fig. 9; van der Werf et al. 1999a, b). As a result of catalytic action of 1,2epoxylimonene hydrolase optically pure $(+)-(1 S, 2 S, 4 R)$ limonene-1,2-diol 30 and unreacted $(+)-(1 S, 2 R, 4 R)-1,2-$ epoxylimonene trans-29 were obtained.

The same microorganism was used to resolve diastereomeric mixture of carveol 32 by selective oxidation. Biotransformation of mixture of (-)-cis-31 and (-)trans-31 in a ratio of 38:62 by $R$. erythropolis DCL14 revealed high stereoselectivity of dehydrogenase. As a result, two optically active products were obtained: (-)$(R)$-carvone $R-17$ and (-)-cis-carveol 31 (Fig. 10; Tecelao et al. 2001; van der Werf et al. 1999a, b).

\section{Future prospects}

Despite intensive studies on whole cells biotransformations of terpenoids, not all issues regarding stability and selectivity have been resolved. In case of water-sensitive compounds, microbial transformations are not a method of choice due to inability of maintaining water-free conditions.
Fig. 8 Profile of reduction of carvone stereoisomers with selected biocatalysts
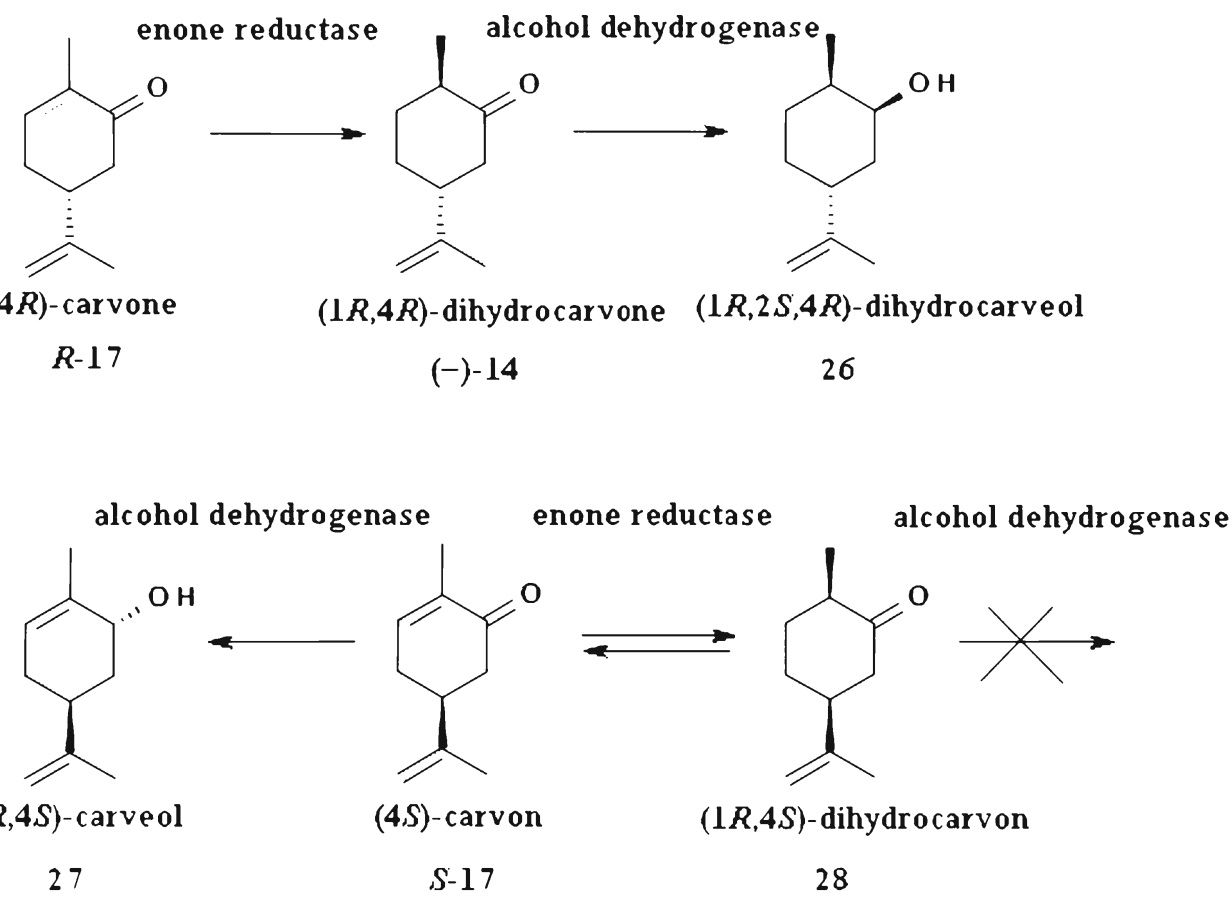
Fig. 9 Kinetic resolution of $(+)-(1 R, 2 S, 4 R)-1,2-$ epoxylimonene and $(+)-$ $(1 S, 2 R, 4 R)-1,2$-epoxylimonene using $R$. erythropolis DCL14 as a biocatalyst

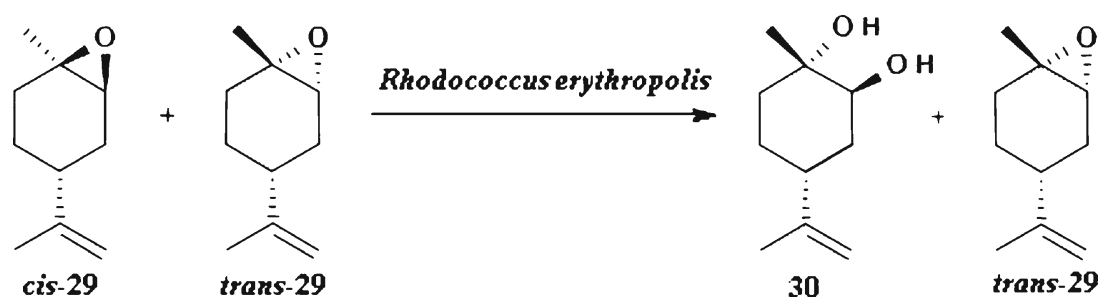

The solution is to carry on transformations with purified enzymes in organic solvents. The major problem of applying microorganisms for biotransformations might be low selectivity like in case of hydrolases. Different enzymes belonging to the same family may have various regio- or stereoselectivity towards transformed compound. Modern studies concentrate on genetic modification of microorganisms towards overexpression and mutations of enzymes useful in biotransformations (Schulz 2007). Wild-type enzymes usually are not well adapted to non-natural substrates which may lead to low conversions or low stereoselectivity. This issue may be overcome by biocatalyst optimization. Genetic screening of microorganisms or screening of metagenomic libraries are useful tools for discovery of new naturally evolved enzymes which may exhibit better properties regarding biotransformation of compound of our interest (Fraaije et al. 2005; Daniel 2004). An alternative method is enzyme engineering of known biocatalysts using site-directed mutagenesis or directed evolution. The first approach is more elegant, gives better results, and often is supported by bioinformatic studies but requires extensive knowledge about enzyme's structure. On the other hand, directed evolution is generally based on creation of library of mutated genes coding biocatalyst, proper plasmid preparation, transformation, and incubation with substrate. A good example is mini-evolution of cyclopentanone monooxygenase which allowed transforming 4methylcyclohexanone into corresponding lactone with $92 \%$ enantiomeric excess compared to the $46 \%$ ee achieved with wild type cyclohexanone monooxygenase (Clouthier et al. 2006).

Wild type or recombined enzymes must be overexpressed in a proper host to be considered as a biocatalyst for large-scale processes. The first kilogram scale Baeyer-Villiger oxidation was reported by Hilker et al.
(2005) where racemic bicyclo[3.2.0]hept-2-en-6-one was converted into two lactones with excellent $e e$ 's: $>98$ and $>99 \%$.

Despite good results, commenced studies over largescale microbial transformations are focused generally on biotransformations of small, nonpolar molecules. The challenge is to develop system suitable for carrying out biotransformation of larger, more polar, and multifunctional compounds.

\section{Conclusion}

Reactions conducted by various microorganisms using terpenoid derivatives as substrates and reviewed in this paper indicate vast possibilities for the production of optically pure compounds using this type of biocatalysts. Optical purity is essential for pharmaceutical and fragrance industry due to possible differences in organoleptic properties and biological activity of isomers. The diversity of microbial activity demonstrates that for each type of reaction it is possible to select proper microorganism that will efficiently and selectively convert substrates into desired products. Modern studies are focused on modification of microorganisms towards overexpression of enzymes of our interest and to enhance desired activity of known enzymes by directed evolution. These studies are particularly valuable to industry due to possibility of carrying out large scale biotransformations.

Acknowledgments This article was supported by the project "Enterprising $\mathrm{PhD}$ studen-an investment in the innovative development of the region" partly financed by the European Union within European Social Foundation and Ministry of Science and Higher Education, grant no NN204 136538.
Fig. 10 Kinetic resolution of $(-)-(4 R, 6 R)$-carveol and $(-)-$ $(4 R, 6 S)$-carveol with $R$. erythropolis DCL14<smiles>C=C(C)[C@H]1CC=C(C)[C@@H](O)C1</smiles>

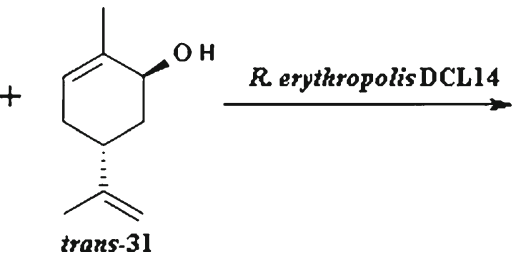<smiles>[R17]C(=C)[C@@H]1CC=C(C)C(=O)C1</smiles> 
Open Access This article is distributed under the terms of the Creative Commons Attribution License which permits any use, distribution, and reproduction in any medium, provided the original author(s) and the source are credited.

\section{References}

Adam W, Mitchell CM, Saha-Moller CR (1999) Steric and electronic effects in the diastereoselective catalytic epoxidation of cyclic allylic alcohols with methyltrioxorhenium (MTO). Eur J Org Chem 4:785-790

Alphand V, Furstoss R, Pedragosa-Moreau S, Roberts SM, Willetts AJ (1996) Comparison of microbiologically and enzymatically mediated Baeyer-Villiger oxidation: synthesis of optically active caprolactones. J Chem Soc Perkin Trans 1:1867-1872

Anderson RJ, Adams KG, Chinn HR, Henrick CA (1980) Synthesis of the optical isomers of 3-methyl-6-isopropenyl-9-decen-1-yl acetate, a component of the California red scale pheromone. J Org Chem 45:2229-2236

Asakawa Y, Takahashi H, Toyota M, Noma Y (1991) Biotransformation of monoterpenoids, $(-)$ - and $(+)$-menthols, terpinolene and carvotanacetone by Aspergillus species. Phytochemistry 30 (12):3978-3981

Auld DS, Bergman T (2008) The role of zinc for alcohol dehydrogenase structure and function. Cell Mol Life Sci 65:3961-3970

Baran PS (2009) Alkane hydroxylation. The Scripps Research Institute. http://www.scripps.edu/baran/images/grpmtgpdf/Voica Mar 09.pdf. Accessed 2 July 2012

Beloqui A, Dominguez de Maria P, Golyshin PN, Ferrer M (2008) Recent trends in industrial microbiology. Curr Opin Microbiol 11:240-248

Bicas JL, Dionisio AP, Pastore GM (2009) Bio-oxidation of terpenes: an approach for the flavor industry. Chem Rev 109:4518-4531

Carballeira JD, Valmaseda M, Alvarez E, Sinisterra Gago JV (2004) Gongronella butleri, Schizosaccharomyces octosporus and Diplogelasinospora grovesii: novel microorganisms useful for the stereoselective reduction of ketones. Enzyme Microb Tech 34:611-623

Carballeira JD, Quezada MA, Hoyos P, Simeo Y, Hernaiz MJ, Alcantara AR, Sinisterra JV (2009) Microbial cells as catalysts for stereoselective red-ox reactions. Biot Adv 27:686-714

Carr K, Saxton HM, Sutherland JK (1988) The $4 \alpha$-demethylation of lanostenone. J Chem Soc Perkin Trans 1:1599-1601

Clouthier CM, Kayser MM, Reetz MT (2006) Designing new BaeyerVilliger monooxygenases using restricted CASTing. J Org Chem 71:8431-8437

Dambolena JS, López AG, Rubinstein HR, Zygadlo JA (2010) Effects of menthol stereoisomers on the growth, sporulation and fumonisin $B_{1}$ production of Fusarium verticillioides. Food Chem 123:165-170

Dancewicz K, Ratuś B, Boratyński F, Kordan B, Gabryś B, Wawrzeńczyk C (2011) Effect of oxygen incorporation into cyclohexanone ring on antifeedant activity. J Plant Protection Res 51:23-28

Daniel R (2004) The soil metagenome-a rich resource for the discovery of novel natural products. Curr Opin Biotechnol 15:199-204

de Carvalho CCCR, da Fonseca MMR (2006) Biotransformation of terpenes. Biotechnol Adv 24:134-142

de Carvalho CCCR, van Keulen F, da Fonseca MMR (2002) Modelling the biokinetic resolution of diastereomers present in unequal initial amounts. Tetrahedron-Asymmetr 13:1637-1643

de Faveri G, Ilyashenko G, Watkinson M (2011) Recent advances in catalytic asymmetric epoxidation using the environmentally benign oxidant hydrogen peroxide and its derivatives. Chem Soc Rev 40:1722-1760 de Maria PD, van Gemert RW, Straathof AJJ, Hanefeld U (2010) Biosynthesis of ethers: unusual or common natural events? Nat Prod Rep 27:370-392

Demyttenaere JCR, Belleghem KV, Kimpe ND (2001) Biotransformation of $(R)-(+)$ - and $(S)-(-)$-limonene by fungi and the use of solid-phase microextraction for screening. Phytochemistry 57:199-208

Esmaeili A, Zarea AH, Sharafian S, Safaiyan S, Rustaiyan A (2009) Biotransformation of menthol by sporulated surface cultures of Penicillium sp. and study of the pathways involved. HerbaPol 1:78-83

Evans DA, Hoveyda AH (1990) Reduction of $\beta$-hydroxy ketones with catecholborane. A stereoselective approach to the synthesis of syn 1,3-diols. J Org Chem 55:5190-5192

Faber K (2000) Biotransformation in organic chemistry. Springer, Heidelberg, pp 177-217

Farooq A, Tahara S, Choudhary I, Rahman A-U, Ahmed Z, Baser KH, Demirci F (2002) Biotransformation of (-)- $\alpha$-Pinene by Botrytis cinerea. Naturforsch 57c:303-306

Fraaije MW, Wu J, Heuts DP, van Hellemond EW, Spelberg JH, Janssen DB (2005) Discovery of a thermostable Baeyer-Villiger monooxygenase by genome mining. Appl Microbiol Biotechnol 66:393-400

Fraga BM, Gonzalez P, Hernandeza MG, Suarez S (2005) Biotransformation of 7-oxo-ent-kaur-16-ene derivatives by Gibberella fujikuroi. Tetrahedron 61:5623-5632

Gładkowski W, Grabarczyk M, Wińska K, Ratuś B, Białońska A, Ciunik Z, Wawrzeńczyk C (2007) Lactones 26: stereoselective microbial epoxidation of unsaturated bicyclic $\gamma$-lactones with the alkylsubstituted cyclohexane system. J Mol Catal-B Enzym 49:79-87

Hilker I, Wolgemuth R, Alphand V, Furstoss R (2005) Microbial transformations 59: first kilogram scale asymmetric microbial Baeyer-Villiger oxidation with optimized productivity using a resin-based in situ SFPR strategy. Biotechnol Bioeng 92:702-710

Hirao A, Itsuno S, Nakahama S, Yamazaki N (1981) Asymmetric reduction of aromatic ketones with chiral alkoxy-amineborane complexes. J Chem Soc Chem Commun 7:315-317

Holland HL (1999) C-H activation. Curr Opin Chem Biol 3:22-27

Holland HL, Weber HK (2000) Enzymatic hydroxylation reactions. Curr Opin Biotech 11:547-553

Hollauf G, Urban E (1995) Synthesis of potential antimicrobial oxiranylisobenzofuranones. Monatsh Chem 126:1203-1212

Ishida T (2005) Biotransformation of terpenoids by mammals, microorganisms, and plant-cultured cells. Chem Biodivers 2:569-590

Itoh T, Jitsukawa K, Kaneda K, Teranishi S (1979) Vanadiumcatalyzed epoxidation of cyclic allylic alcohols. Stereoselectivity and stereocontrol mechanism. J Am Chem Soc 101:159-169

Kamerbeek NM, Janssen DB, van Berkel WJH, Fraaije MW (2003) Baeyer-Villiger monooxygenases, an emerging family of flavin dependent biocatalysts. Adv Synth Catal 345:667-678

Kołek T, Szpineter A, Świzdor A (2009) The microbiological hydroxylation of patchoulol in Absidia coerulea and Mucor hiemalis. Biocatal Biotransfor 27:102-106

Kuriata R, Gajcy K, Turowska-Tyrk I, Lochyński S (2010) Stereochemistry of terpene derivatives. Part 6: chemoenzymatic synthesis of chiral bicyclo[3.1.0]hexane derivatives with olfactory properties. Tetrahedron-Asymmetr 21:805-809

Kuriata-Adamusiak R, Strub D, Szatkowski P, Lochyński S (2011) Biotransformation of bicyclic terpenoid ketones towards new compounds with olfactory properties. Flavour Fragr J 26:351-355

Li Z, Van Beilen J, Duetz WA, Schmid A, de Raadt A, Griengl H, Witholt B (2002) Oxidative biotransformations using oxygenases. Curr Opin Chem Biol 6:136-144

Lochyński S, Frąckowiak B, Librowski T, Czarnecki R, Grochowski J, Serda P, Pasenkiewicz-Gierula M (2002) Stereochemistry of terpene derivatives. Part 3: hydrolytic kinetic resolution as a convenient approach to chiral aminohydroxyiminocaranes with local anaesthetic activity. Tetrahedron-Asymmetr 13:873-878 
Meunier B, de Visser SP, Shaik S (2004) Mechanism of oxidation reactions catalyzed by cytochrome P450 enzymes. Chem Rev 104:3947-3980

Mihovilovic MD, Mueller B, Stanetty P (2002) Monooxygenasemediated Baeyer-Villiger oxidations. Eur J Org Chem 22:37113730

Mironowicz A, Siewinski A (1986) Biotransformations. XIX. Reduction of some terpenic ketones by means of immobilized cells of Rhodotorula mucilaginosa. Acta Biotechnol 6:141-146

Miyazawa M, Kawazoe H, Hyakumachi M (2002) Biotransformation of 1-menthol by soil-borne plant pathogenic fungi (Rhizoctonia solani). J Chem Technol Biotechnol 77:21-24

Miyazawa M, Kawazoe H, Hyakumachi M (2003) Biotransformation of $l$-menthol by twelve isolates of soil-borne plant pathogenic fungi (Rhizoctonia solani) and classification of fungi. J Chem Technol Biotechnol 78:620-625

Moniczewski A, Librowski T, Lochyński S, Strub D (2011) Evaluation of the irritating influence of carane derivatives and their antioxidant properties in a deoxyribose degradation test. Pharm Rep 63:120-129

Naik HG, Yeniad B, Koning CE, Heise A (2012) Investigation of asymmetric alcohol dehydrogenase (ADH) reduction of acetophenone derivatives: effect of charge density. Org Biomol Chem 10:4961-4967

Nakamura K (1998) Highly stereoselective reduction of ketones by Geotrichum candidum. J Mol Catal-B Enzym 5:129-132

Nakamura K, Takenaka K, Fujii M, Ida Y (2002) Asymmetric synthesis of both enantiomers of secondary alcohols by reduction with single microbe. Tetrahedron Lett 43:3629-3631

Neufeldt SR, Sanford MS (2012) Controlling site selectivity in palladium-catalyzed C-H bond functionalization. Accounts Chem Res 45:936-946

Nidiry ESJ (2003) Quantitative structure-fungitoxicity relationships of some monohydric alcohols. J Agric Food Chem 51:5337-5343

Norris DB, Trudgill PW (1971) The metabolism of cyclohexanol by Nocardia globerula CL 1. Biochem J 121:363-370

Omolo MO, Okinyo D, Ndiege IO, Lwande W, Hassanali A (2004) Repellency of essential oils of some Kenyan plants against Anopheles gambiae. Phytochemistry 65:2797-2802

Ottolina G, Carrea G, Collonna S, Ruckemann A (1996) A predictive active site model of cyclohexanone monooxygenase catalyzed Baeyer-Villiger oxidation. Tetrahedron-Asymmetr 7:1123-1136

Pinheiro L, Marsaioli AJ (2007) Microbial monooxygenases applied to fragrance compounds. J Mol Catal-B Enzym 44:78-86

Renz M, Meunier B (1999) 100 years of Baeyer-Villiger oxidations. Eur J Org Chem 4:737-750

Roberts SM, Wan PW (1998) Enzyme-catalyzed Baeyer-Villiger oxidation. J Mol Catal B-Enzym 4:111-136

Robinson DEJE, Bull SD (2003) Kinetic resolution strategies using non-enzymatic catalysts. Tetrahedron-Asymmetr 14:1407-1446
Schulz F (2007) Monooxygenases: experiments to turn a class of enzymes into a toolbox for biocatalysis. Dissertation, University of Bochum

Secundo F, Carrea G, Riva S, Battistel E, Bianchi D (1993) Cyclohexanone monooxygenase catalyzed oxidation of methyl phenyl sulfide and cyclohexanones with macromolecular NADP in a membrane reactor. Biotech Lett 15:865-870

Serra S, Brenna E, Fuganti C, Maggioni F (2003) Lipase-catalyzed resolution of $p$-menthan-3-ols monoterpenes: preparation of the enantiomer-enriched forms of menthol, isopulegol, trans- and cispiperitol, and cis-isopiperitenol. Tetrahedron Asymmetr 14:33133319

Tecelao CSR, van Keulen F, da Fonseca MMR (2001) Development of a reaction system for the selective conversion of (-)-trans-carveol to (-)-carvone with whole cells of Rhodococcus erythropolis DCL14. J Mol Catal-B Enzym 11:719-724

van der Werf MJ, Orru RVA, Overkamp KM, Swarts HJ, Osprian I, Steinreiber A, de Bont JAM, Faber K (1999a) Substrate specifcity and stereospecifcity of limonene-1,2-epoxide hydrolase from Rhodococcus erythropolis DCL14; an enzyme showing sequential and enantioconvergent substrate conversion. Appl Microbiol Biotechnol 52:380-385

van der Werf MJ, van der Ven C, Barbirato F, Eppink MHM, de Bont JAM, van Berkel JH (1999b) Stereoselective carveol dehydrogenase from Rhodococcus erythropolis DCL14. J Biol Chem 274:26296-26304

van Dyk MS, van Rensburg E, Rensburg IPB, Moleleki N (1998) Biotransformation of monoterpenoid ketones by yeasts and yeast-like fungi. J Mol Catal-B: Enzym 5:149-154

Vaz ADN, McGinnity DF, Coon MJ (1998) Epoxidation of olefins by cytochrome P450: evidence from site-specific mutagenesis for hydroperoxo-iron as an electrophilic oxidant. Proc Natl Acad Sci USA 95:3555-3560

Walton NJ, Brown DE (1999) Chemicals from plants: perspectives on plant secondary products. Imperial College Press, London

Wincza E, Lochyński S (2012) Chemical and microbiological oxidation of (-)-cis-carane-4-one leading to chiral compounds and evaluation of their antifeedant activity ARKIVOC 2012(iv):196-203

Ying X, Ma K (2011) Characterization of a zinc-containing alcohol dehydrogenase with stereoselectivity from the hyperthermophilic Archaeon Thermococcus guaymasensis. J Bacteriol 193:30093019

Zanotti-Gerosa A, Hems W, Groarke M, Hancock F (2005) Ruthenium-catalyzed asymmetric reduction of ketones. Platinum Metals Rev 49:158-165

Zhu D, Stearns JE, Ramirez M, Hua L (2006) Enzymatic enantioselective reduction of $\alpha$-ketoesters by a thermostable $7 \alpha$ hydroxysteroid dehydrogenase from Bacteroides fragilis. Tetrahedron 62:4535-4539 